\title{
O SONETO E A MÚSICA: LUÍS MILÁN, JORGE DE MONTEMÓR E LUÍS DE CAMÕES
}

\section{SONNET AND MUSIC: LUÍS MILÁN, JORGE DE MONTEMAYOR AND LUÍS DE CAMÕES}

Sheila Hue

\begin{abstract}
RESUMO
O artigo busca demonstrar que o soneto, na época de Camões, era também cantado, e com acompanhamento musical, o que contraria a noção tradicional do "divórcio entre a música e a poesia". Para tanto, procura iluminar o cenário cortesão das práticas poéticas e musicais trazendo à discussão os livros de vihuela, El Cortesano, de Luís Milán, e La Diana, de Jorge de Montemór.
\end{abstract}

PALAVRAS-CHAVE: soneto, música e poesia; Luís Milán; Luís de Camões; Jorge de Montemór.

\section{ABSTRACT}

This paper intends to demonstrate that, in Camões's period, the sonnet was also sung, with musical accompaniment, a practice that contradicts the traditional concept of a "divorce between music and poetry". To show this, the courtly scenario is explored through the discussion of the vihuela books, LuísMilán's El Cortesano and Jorge de Montemayor's La Diana.

KEYWORDS: sonnet, musicandpoetry; Luís Milán; Luís de Camões; Jorge de Montemayor. 
A história literária talvez tenha registrado de forma assaz pétrea a concepção de que a partir da geração de Dante, e mais especificamente após a publicação de Vida nova, ocorre o "divórcio entre a poesia e a música". A expressão, que teve grande fortuna inclusive em histórias da literatura portuguesa escritas no Brasil, é usada quase sempre no sentido de indicar que a poesia passou a ser fruída somente por meio da leitura - seja individual e silenciosa, seja em voz alta e em grupo -, sem acompanhamento musical e sem o canto. O "divórcio entre a poesia e a música" significaria, portanto, que a poesia não é mais cantada ou executada com instrumentos musicais a partir de então. Tal "divórcio" viria a se opor diametralmente ao "casamento” entre música e poesia na época dos trovadores medievais. Alberto Roncaglia, entretanto, observa que "a noção de 'divórcio entre a música e a poesia’, por ela mesma ambígua, representa em realidade não um ato simples e súbito de separação, mas sobretudo a última etapa de um processo de individualização intrinsecamente complexo"2 (RONCAGLIA, 1978, p.367). O que ocorre a partir da geração de Dante, ou da poesia siciliana anterior, parece ser mais a autonomia da poesia frente à música, ou seja, a independência da criação literária, não mais totalmente vinculada à performance musical como ocorria na cultura dos trovadores, do que uma separação radical entre a letra e a execução musical, cuja união continuou ocorrendo. Mesmo na obra de Dante há referências à poesia cantada e tocada. No De vulgarieloquentia, ao discorrer sobre o gênero canção, apesar de observar que a poesia existe nas letras do livro separadamente da execução musical, Dante indica que é naturalmente destinada ao canto (BELTRAMI, 1999, p.195). No "Purgatório", da Divina comédia, há o episódio em que o cantor florentino Casella, figura notória em sua época, canta e toca a canção - recolhida no Convívio do próprio Dante - "Amor che ne la mente mi ragiona", testemunhando que o gênero poético, também presente na Vida nova, era corriqueiramente fruído em performance musical.

A principal mudança ocorrida, da cultura dos trovadores para a nova poesia italiana, seria não um total divórcio entre a música e a poesia, mas, segundo o filólogo Pietro G. Beltrami, o desaparecimento da figura do poeta-músico medieval, que dá lugar ao poeta literato e não mais necessariamente músico. Se a poesia passa a ser escrita não mais dependente de uma melodia musical, isto não impede que a letra seja musicada por outros ou que melodias sejam empregadas para cantá-la ou recitá-la (1999, p.198199). Alguns gêneros, segundo Beltrami, não precisariam necessariamente de acompanhamento instrumental; entre eles, figurava o soneto, gênero de forma fixa criado entre os sicilianos no século XIII (1999, p. 203). Entretanto, mesmo que isso não ocorresse entre os contemporâneos de Giacomo da Lentini, seu pretenso inventor, na corte de Federico II, já no século XV o sonetoera cantado e tocado, em uma prática em que a mesma melodia servia para cantar quartetos e tercetos de um soneto e também outros gêneros de poemas, como os Triunfos de Petrarca em terza rima, segundo o musicólogo Nino Pirrotta (1985, p.462). Tratava-se de uma nova forma de musicalização da poesia na Itália, relacionada então ao Humanismo. 
No que concerne à poesia portuguesa, em recente artigo Marcia Arruda Franco chama a atenção para a face musical do Cancioneiro geral de Garcia de Resende (Lisboa, 1516), refutando a tradição crítica do "divórcio entre a música e a poesia" após a época dos trovadores, e comprovando o emprego dos poemas cancioneiris em práticas de sociabilidade cortesãs:

Entretanto, ao ser impresso sem a notação musical, com o intuito expresso de preservar a memória das trovas, o cancioneiro resendiano não se liberta da música nem no modo espetacular do seu proferimento nem no modo conjunto de sua produção. Ao contrário, o cancioneiro palaciano, impresso, manuscrito e pela memória músico-vocal, fomentará a difusão e cultivo, ao vivo, em performance, das trovas cantadas e musicadas, nos variados saraus da corte portuguesa e ibérica, ao longo de muitas gerações, o que se evidencia na referência a seus trovadores-músicos até pelo menos ao século XVII. (FRANCO, 2017, p.106)

No presente artigo, gostaria de trazer alguns aportes que nos permitam pensar alguma poesia de Camões, e também de seus contemporâneos, e especialmente os sonetos, como poesia musical, não dependente da música e do canto ou criada especificamente para a música, mas como poesia eventualmente empregada no cenário das cortes e dos salões, apresentada com canto e acompanhamento instrumental, especialmente o canto monódio e a viola de mão (a vihuela, viola tocada sem arco). Para isso, começo por trazer ao cenário algumas obras impressas quando Camões já vivia e que devem provavelmente ter chegado ao conhecimento dos letrados portugueses de seu tempo, e especialmente dos poetas, figuras fundamentais nas cortes e nos salões onde a poesia circulava oralmente. Numa primeira etapa, veremos os livros musicais publicados na Espanha no século XVI, particularmente os de Luís Milán, que traziam sonetos e outros "novos" gêneros poéticos musicados, e em segundo lugar nos voltaremos para as práticas musicais poéticas constantes em La Diana, de Jorge de Montemór, contemporâneo de Camões.

O Libro de música de vihuela de mano intitulado El maestro, impresso em Valência, em 1536, composto pelo vihuelista, compositor e poeta Luís Milán (c. 1500-c. 1561), é dedicado "al muy alto muy poderoso invictissimoprinicipe Don Juhan, por la gracia de Dios, rey de Portugal y de las yslas, etc.", como registra o título. Na página seguinte ao frontispício, uma gravura do rei português D. João III, ladeada pelas palavras "InvictissimusRexLusitanorum", pousa sobre o brasão de armas do monarca, e é rodeada por elaborada moldura, encimada por anjos e ladeada por colunas decoradas com motivos florais.

O patrocínio do rei português ao livro é reforçado na epístola dedicatória, na qual Luís Milán declara que seria ingrato com quem "lhe deu saber para escrever tal livro" mantê-lo apenas para si e não o divulgar. El maestro, segundo Milán argumenta na epístola, em uma elegante fábula 
moral, é como uma joia jogada ao mar que termina por chegar às mãos de seu verdadeiro dono e merecedor, D. João III. Na conclusão da dedicatória, Milán arremata a argumentação: seu livro de música pertence ao rei português porque Portugal é "la mar de la música", pois no país tanto estimam quando entendem a música (1536, fl.iii). Portugal seria, desta forma, o país músico por excelência, protetor e destinatário ideais do primeiro livro de música do gênero.

Não há registros documentais que atestem a presença de Milán na corte de D. João III, mas a familiaridade com que o autor trata o monarca em sua epístola dedicatória e a referência a Portugal como um país músico, em um livro escrito em castelhano e publicado em Valência por um valenciano, parece depor afirmativamente em relação a essa hipótese. Como observa Paloma Otaola González no artigo "Poesía italiana en los libros de música para vihuela dl siglo XVI", "El Maestroestá dedicado a Juan III de Portugal por lo que suele pensar que Milán residió un tiempo en este país aunque no se sabe cuándo exactamente ni cuales eran sus vínculos con la corte portuguesa" (2012, p. 322).

El maestro, ou "o professor", pretende ser uma obra didática, um manual escrito para ensinar ao principiante a arte de tocar a vihuela - o instrumento cortesão ibérico presente nas cortes e nas casas - por meio de pormenorizados ensinamentos técnicos, tablaturas de cifras musicais, algumas acompanhadas das letras dos poemas musicados, cujos versos vêm escritos abaixo da partitura, com as sílabas musicalmente escandidas para o canto. É de notar que Milán explique, logo no início, que, para aprender a tocar a vihuela, é necessário primeiro saber cantar, indicando como o instrumento estava ligado à voz. No oitavo caderno de El maestro, encontra-se música para cantar e tocar, "vilancicos y cosas italianas", como explica o sumário. Entre as coisas italianas, figuram dois sonetos.

A ligação com a poesia começa a aparecer na dedicatória a D. João III, que principia com uma citação de Petrarca, para explicar que Luís Milán era músico por inclinação das estrelas assim como o livro pertencia a Portugal por este ser um reino destinado a ser musical:

Muy alto catholico y poderoso principe Rey y señor, el muy famoso Francisco Petrarchadize en su sonetos y triumphos que cada uno nosotros sigue su estrela, con estas palabras: Ognium seque suastella. Afirmando que nascemos debaxo de una estrela a la qual somos sometidos por inclinación [...] (MILÁN, 1536, fol. iii).

Uma gravura de página inteira no fólio VI estampa Orfeu, o deus grego, tocando uma vihuela ibérica tendo a seu lado os animais encantados por sua música. Na moldura, os dizeres: "El grande Orpheo/ primeiro inventor por quienlavihuela/ parece enel mundo" (1536, fl. vi). Orfeu estaria, portanto, na origem da vihuela. A ligação entre música, poesia e canto é evidenciada no oitavo caderno do livro, no qual a voz com acompanhamen- 


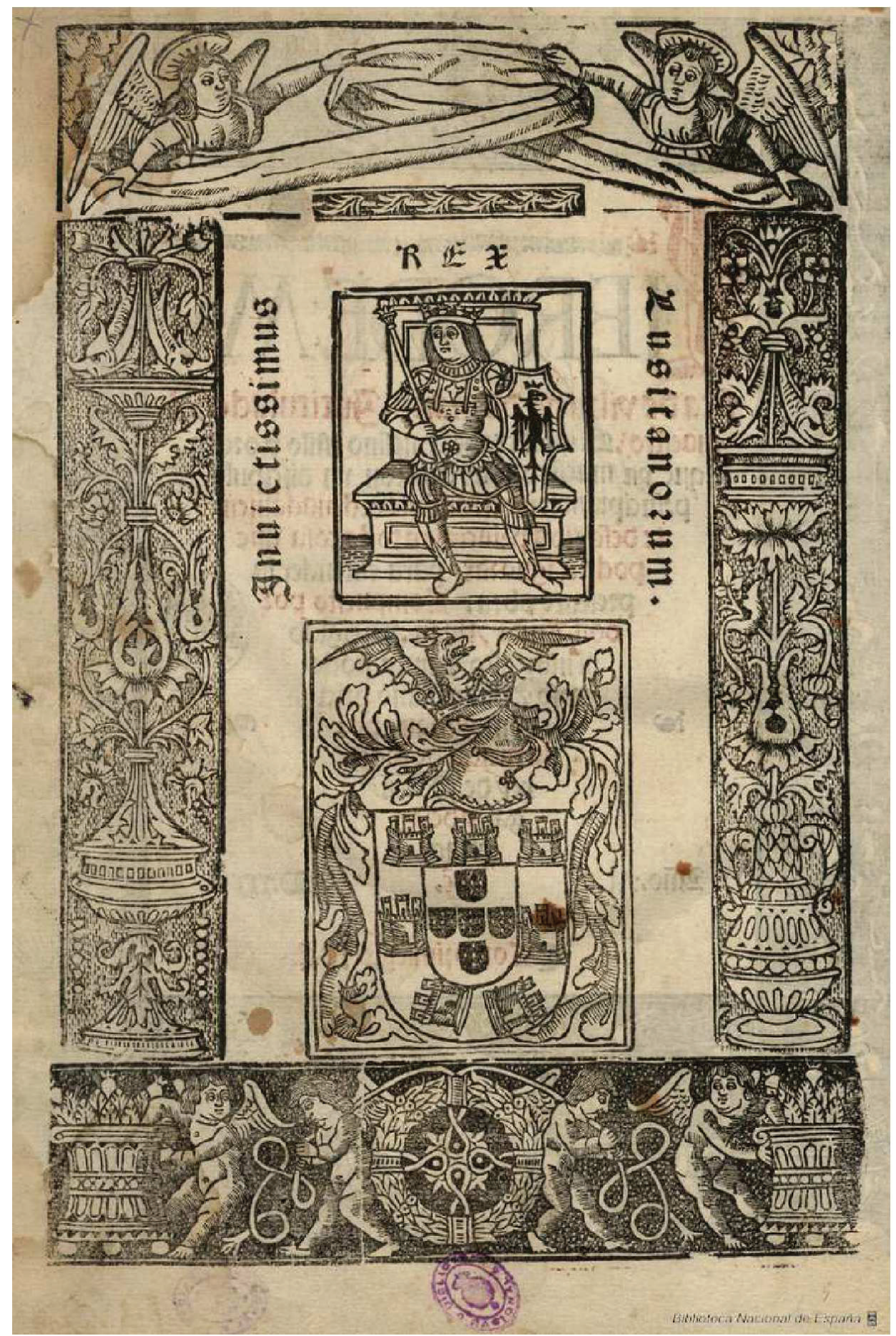

Gravura do rei D. João III impressa no Libro de música de vihuela de mano intitulado El maestro. Fonte: acervo da Biblioteca Nacional da Espanha. 
to instrumental é a tônica, como se percebe pelas detalhadas indicações de interpretação vocal - "el cantor puedehacer garganta" (floreios com a voz); "el cantor ha de cantar llano". Nele, encontramos 22 poemas em castelhano, português e italiano (CASTAGNA, 1996), que provavelmente compunham um repertório compartilhado por Espanha e Portugal. Em castelhano e português há vilancicos e romances com tema de amor profano. Em italiano, dois sonetos, um de Francesco Petrarca ("Amor chenelpenser mio vive et regna”)e outro de JacopoSannazaro (“Ó gelosia, d’amantihorribil freno"), musicados com composições originais de Milán, e, ainda, trechos de poemas decassílabos musicados - estes também classificados de "sonetos" pelo autor.

El maestro, o primeiro livro de música para vihuela a ser impresso, em 1536, traz a música imbricada à poesia, descrevendo a performance musical de instrumento e voz, em que melodia e palavra fazem parte de um mesmo conjunto. A poesia cantada havia ganhado um novo impulso no século XVI, quando o ideal grego da união entre música e poesia inspirou, na Península Ibérica, como observa Paloma Otaola González(2012, p.321), o florescimento da monodia (canto a uma só voz) acompanhada pela vihuela, ocorrido paralelamente ao do madrigal polifônico (canto a várias vozes). A gravura de Orfeu com a vihuela hispânica em El maestro de Luís Milán é a representação iconográfica dessa assertiva.

O repertório para voz e vihuela, a partir de El maestro, foi publicado em vários livros impressos, todos com a inclusão de poemas a serem cantados a uma só voz acompanhados pelo instrumento, provavelmente respondendo a uma demanda do público por este gênero de obras que visavam à reprodução doméstica de peças musicais instrumentais e cantadas. A publicação desses livros responde a uma ampliação do mercado para o livro de música impresso e dos setores nele interessados. Dez anos depois de El maestro, clérigo Alonso Mudarra (c. 1510-1580) publicaTreslibros de musicaen cifra para vihuela, em que se encontram partituras musicais para sonetos de Petrarca ("La vitafugge") e de Sannazaro ("Ó gelosia d'amanti", o mesmo musicado por Milán), e para outros poemas decassílabos italianos. Mudarra inclui em seu repertório, a ser tocado e cantado pelos leitores do livro nas casas e nas cortes, não apenas os grandes autores consagrados, já clássicos. Publica também poetas novos, autores espanhóis contemporâneos, os introdutores da "nova poesia" ao modo italiano na Península Ibérica, Juan Boscán (1492-1542) e Garcilaso de la Vega (1503-1536). Um dos poemas espanhóis impressos por Mudarra é o célebre soneto "Por ásperos caminoshellegado", de Garcilaso. Na época da publicação do livro de $\mathrm{Mu}$ darra, a poesia de Boscán e Garcilaso, que tinha corrido manuscrita, fora publicada havia apenas três anos, em 1543, mas seria muitas vezes reimpressa, caindo no gosto do público. "Por ásperos caminoshellegado" era, portanto, um poema da moda, musicado e impresso, para que os leitores o executassem em seus saraus. No Libro de música de vihuela, de Diego Pissador, impresso em Salamanca em 1552, encontramos no prólogo a informação de que o volume servia para a recreação, para os momentos de lazer, 


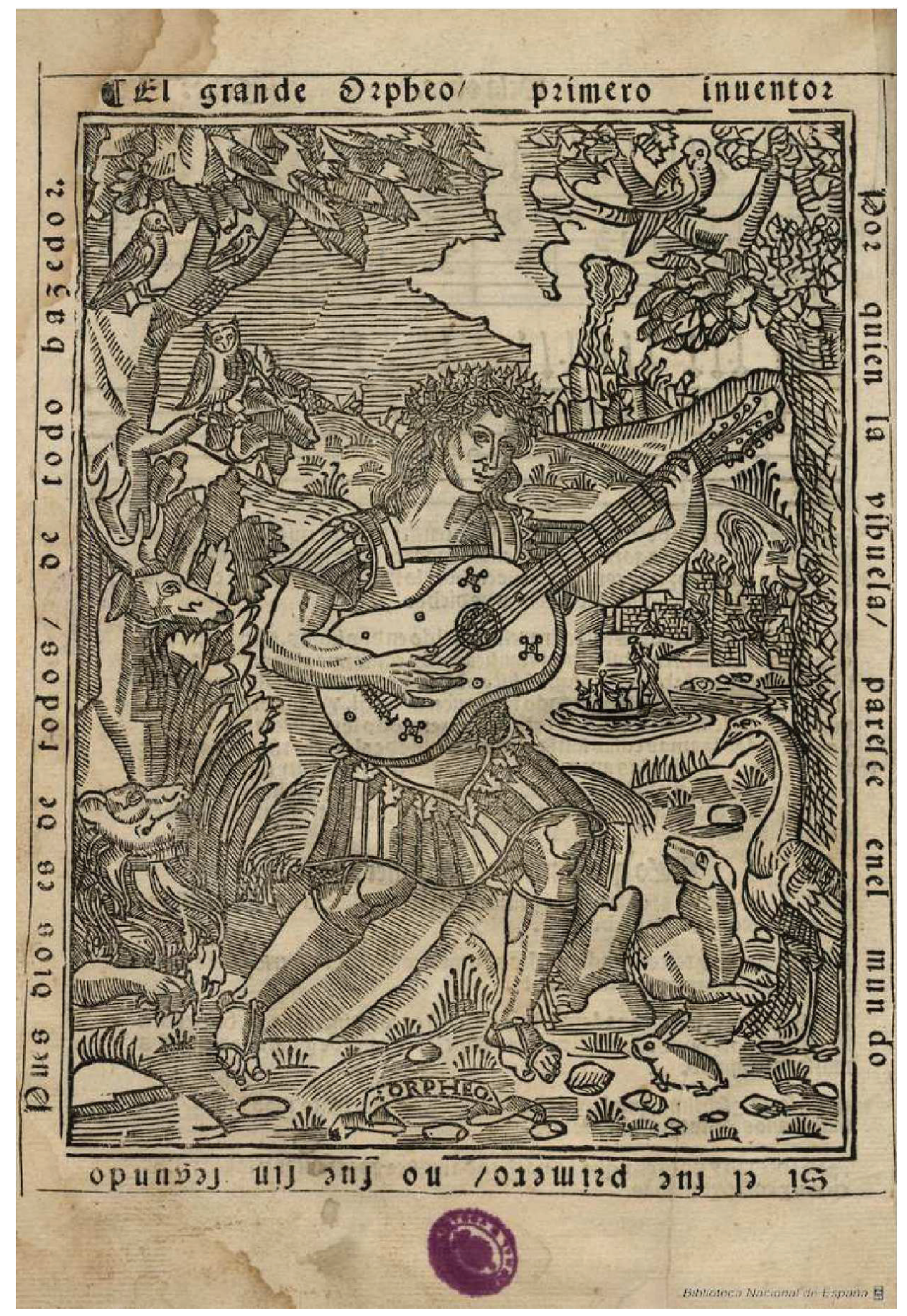

Orfeu tocavihuela ibérica. Fonte: acervo da Biblioteca Nacional da Espanha. 
um livro pelo qual se podia "tanger y cantar". Os livros de vihuela retratam, mesmo que indiretamente, algumas práticas poéticas do período, ilustrando como a poesia era realizada e fruída em performance, em presença, envolvendo um grupo de pessoas e atuações musicais, vocais e corporais.

Ignacio López Almany, no artigo "El sonsoneto y lapráctica poética cortesanadelsiglo XVI”, observa que José Manuel Blecua, IgnacioNavarrete e Maria José Vega já haviam notado que os vihuelistas tiveram um importante papel na difusão e popularização da nova poesia ao modo italiano, escrita em decassílabos (2016, p. 584), que inicialmente sofreu resistência por parte dos tradicionalistas, defensores do metro (a redondilha) e dos gêneros do lirismo ibérico. É de notar que essa introdução da nova poesia ao modo itálico se deu com trechos musicados de poemas maiores (como canções, éclogas, epístolas e epodos) e também com os poemas curtos, como o soneto para ser cantado por uma só voz e acompanhado pela vihuela em ambiente cortesão. $\mathrm{O}$ entretenimento em ambientes da corte, a julgar pelos livros de Milán e de Mudarra, e os de outros autores, incluía, portanto, o soneto musicado e cantado, ou seja, o gênero fixo de 14 versos decassílabos, dividido em quartetos e tercetos, atuando como poesia performativa, dependente da voz, da música e de uma plateia. Como havia uma intensa circulação de livros entre Espanha e Portugal, podemos inferir que tais livros eram também de conhecimento dos estratos letrados da sociedade portuguesa, e que se prestavam a usos semelhantes entre os leitores portugueses, sendo obras que se empregavam não apenas para a leitura individual mas para a prática musical pública, para o entretenimento cortesão.

Como observa Bruno M. Damiani, os vihuelistas viam o seu instrumento como um descendente da lira clássica, ou mesmo como a própria lira em uma versão moderna. Portanto, concebiam a música para voz e vihuela como uma ressurreição da canção clássica acompanhada pela lira (1984, p.441).E, como nota Paloma Otaola González no artigo "Poesia italiana enloslibros de música para vihueladelsiglo XVI", a prática do soneto cantado na Península Ibérica está diretamente relacionada ao Humanismo:

La presencia del soneto de Sannazaro en dos libros de música para vihuela es una manifestación más de la presencia de la poesía italiana en suelo ibérico, también en la forma de poesía cantada con acompañamiento musical. Esta manera de interpretar la poesía recibe un nuevo impulso en el Renacimiento, al tiempo que se desarrolla cada vez más la música instrumental. Milán y Mudarra son los únicos vihuelistas que componen una melodía original para los sonetos en italiano, ya que los demás se limitan a adaptar a la vihuela composiciones polifónicas ya existentes. Las dos versiones de $O$ gelosia, distantes de unos diez años, muestran la evolución estética de la música vocal profana que adopta por un lado la escritura polifónica propia de la música sacra, que se impone con los compositores flamencos y por otro, el gusto por la monodia acompañada de clara influencia humanista (2012, p. 329). 
A prática do canto monódico do soneto com acompanhamento musical pode ser vista também no Libro de música de vihuela (1552), de Diego Pissador, quando Boscán e Garcilaso já corriam em edições impressas. Nesse livro, Pisador musica um dos sonetos mais famosos deste último, "Passando el mar Leandro". Este mesmo soneto havia sido impresso em Portugal, sem nome de autor, num panfleto de quatro fólios, em 1536, intitulado Trovas de dous pastores[...] (ALATORRE, 1975, p.149), indicando que o poema era popular também em Portugal. O tema de Leandro e Hero, de grande fortuna no período, será objeto de muitos sonetos, como os dos portugueses Luís de Camões, Diego Bernardes e Pero de Andrade Caminha. Em um sistema literário ibérico, com forte e intensa troca e partilha cultural, não seria de estranhar que poetas portugueses conhecessem a versão musicada de Garcilaso, poeta modelo para a geração de Camões, e que a prática do soneto cantado atravessasse a fronteira entre os dois reinos juntamente com os homens que circulavam de um lado a outro. Podemos ainda inferir que as folhas volantes de poesia, como a Trovas de dous pastores [...] e Passandoel mar Leandro ${ }^{3}$, que trazem em seus frontispícios os títulos dos poemas como anúncios de primeira página de jornal, o que indica seu consumo popular, poderiam ser empregadas também como livros de música, guias para cantar os poemas, como o referido soneto de Garcilaso, para o que se usavam melodias genéricas, adaptáveis a vários textos. O "Romance de Belerma", por exemplo, publicado na mesma folha volante portuguesa de 1536 e anunciado no frontispício, era um cantar velho popularmente entoado ${ }^{4}$ :

\author{
O Belerma, ó Belerma, \\ Por mi mal foste engendrada \\ Que siete anos te servi \\ Sin de ti alcançar nada \\ Agora que me querias \\ Muero me nesta batalla \\ [...] $(1536$, fl.4)
}

O hábito de cantar romances, cantigas e trovas com acompanhamento de instrumento de corda em Portugal é registrado em obras quinhentistas portuguesas, como no Filodemo de Camões, em que as personagens cantam acompanhando-se da viola, e como em diversas passagens da Aulegraphia, de Jorge Ferreira de Vasconcelos - numa cena cômica citada por Teófilo Braga, um pajem para se distrair juntamente com o companheiro canta à guitarra o romance $O$ rapaz do Conde Daros até que uma corda do instrumento se rompe (BRAGA, 1871, p. 298). A inclusão, na folha volante portuguesa, do soneto de Garcilaso ao lado de gêneros poéticos tradicionais ibéricos que se prestavam ao canto e à música - como o romance - parece indicar que as tradicionais formas de entretenimento tenham absorvido as composições em decassílabo e os novos gêneros poéticos italianos que começavam a penetrar em Portugal. 
A popularidade da vihuela em Portugal no século XVI é atestada pelo fundamental artigo do musicólogo Manuel de Morais, "A viola de mão em Portugal (c.1450-c.1789)”, em que aprendemos também que vários violeiros atuantes nas cortes portuguesas eram espanhóis (2006, p.400), o que demonstra o quanto as práticas musicais, o repertório e os livros de música deveriam ser compartilhados entre os reinos ibéricos. A viola de mão em Portugal era tocada "de forma erudita num círculo bastante restrito, ligado quase sempre à corte portuguesa ou a alguma casa senhorial. Tangid[a] pelos seus músicos de câmara, até por escudeiros e fidalgos [...]" (MORAIS, 2006, p. 397). Curiosamente, a única vihuela quinhentista conhecida é portuguesa, feita pelo violeiro Belchior Dias, em Lisboa, em 1581, como registra uma inscrição do instrumento, que hoje se encontra na coleção do Royal Collegeof Music, em Londres.

O soneto cantado e musicado é uma prática corrente na França a partir da publicação de Amours, de Pierre Ronsard (1524-1585), em 1552. O livro incluía um suplemento musical, no qual colaboraram quatro compositores franceses, com pautas musicais para acompanhamento dos sonetos, gênero poético novo na poesia francesa. Este suplemento musical, segundo Jean Vignes, "é uma realização decisiva para efetivar a união entre a poesia e a música, ardentemente desejada pelos humanistas em geral e por Ronsard em particular"5(2016, p.6). No prólogo ao leitor dos Amours, o poeta da Plêiade dirige-se a seu público: "Fiz imprimir, e incluí no final do presente livro, a Música, com a qual tu poderás cantar uma boa parte do conteúdo do mesmo"6 (apudOUVRAD, 1988, p. 152). Posteriormente, os sonetos do livro foram musicados por diversos compositores franceses que, na década de 1570, publicaram uma série de livros impressos com as pautas musicais (Sonnetz de Pierre de Ronsard, de Philippe de Monte, Sonetz de P. Ronsard, mis em musique par Guillaume Boni, etc.), provavelmente um reflexo de uma verdadeira moda do soneto cantado (OUVRARD, 1988, p.149-150). Em 1565, na sua arte poética, Abbrégé de l'artpoetiquefrançois, Ronsard, que é exatamente da mesma geração de Camões, explicita a união entre música e poesia, dá conselho aos poetas ensinando que alternar versos masculinos e femininos facilita o trabalho dos compositores ao musicarem os poemas, e faz uma das mais conhecidas declarações do livro:“[...] pois a poesia sem os instrumentos, ou sem a graça de uma só ou de muitas vozes, não é nem um pouco agradável, não mais do que os instrumentos sem serem animados pela melodia de uma agradável voz" ${ }^{7}$ (RONSARD, 1903, p.8).

Semelhante atitude parece ter movido os autores de livros de música para vihuela, como Luís Milán, que publicou ainda duas obras, o Libro de motes de damas y caballeros(1535), que reúne motes para jogos de salão, e uma obra extremamente interessante,Libro intituladoEl cortesano, uma imitação do diálogo Il libro delcortegiano, de BaldassareCastiglione - grande sucesso italiano difundido por toda a Europa e traduzido em espanhol por Juan Boscán. El cortesano, de Luís Milán, impresso em Valência em 1561, e dedicado ao rei espanhol Felipe II também numa elegante e erudita 
epístola, visava fornecer às cortes espanholas, ou mesmo ibéricas, modelos de conduta cortesã, ou, como ele mesmo diz, o livro "dá modos e avisos" sobre uma série de práticas de salão, incluindo conversas elegantes, dizeres agudos, disputas poéticas, burlas "a modo de palácio", respostas e réplicas.

O livro é uma reunião de diferentes gêneros, trazendo romance, teatro, trovas, glosas, emblemas, além dos sonetos, poemas de autoria do próprio Milán. Em sua face pedagógica de diálogo dirigido à corte do rei espanhol, como explicita a dedicatória do livro, representa um ideal de corte civilizada para a época de Felipe II. A modo de diálogo, como seu modelo italiano, El cortesano se passa ao longo de seis jornadas em Valencia, na corte do Duque da Calábria e de sua esposa Germana de Foix, ao longo das quais as personagens - entre elas, o próprio Luís Milán - caçam, conversam, jogam, divertem-se, disputam, falam ditos espirituosos e contos, compõem poemas de repente, assistem a peças de teatro e se entretêm com passatempos cortesãos e com música e poesia. Mesmo que a jornadas não correspondam aos eventos ocorridos na corte valenciana do Duque da Calábria, podemos dizer que refletem algumas práticas reais da poesia cortesã do século XVI na Península Ibérica. Entre as práticas descritas encontra-se a realização musical de uma série de gêneros poéticos, como motes, coplas, romances, vilancicos, e também da nova poesia ao modo italiano - que em Portugal se denominou "medida nova" - e especialmente do soneto, performances musicais de canto acompanhado pela vihuela, entremeadas pelas conversas entre os cortesãos. Em alguns trechos o soneto passa a ser um elemento subalterno e dependente das criativas práticas cortesãs, envolvendo motes, ditos espirituosos, emblemas, enigmas, contos, servindo como contraponto ou comentário aos temas tratados na conversação. Mas, em outros momentos, assume um papel central.

Ignacio López Alemany observa que um bom modo para conhecer a realidade performativa dos sonetos no entretenimento cortesão é estudar a forma como são empregados em El cortesano (2016, p.585). Ao longo do último capítulo do livro, encenam-se diferentes dinâmicas envolvendo sonetos, exibindo múltiplas formas de realização oral e de fruição da peça poética. Temos desde a performance musical do soneto, com canto e vihuela - realizada pelo próprio “D. Luís Milán”, um dos cortesãos presentes no livro -, até práticas de interpretação do poema em forma de diálogo.

É na última jornada de El cortesano, portanto, que ocorrem mais intensamente as práticas cortesãs envolvendo poesia e música. A jornada começa com Milán dizendo a que veio naquele dia: "yovengo esta noche para hacerun descargo del cargo que tenía [...] de tañer y cantar[...]. Y denme la vihuela que me han traido y cantaré con esta primera obra las obras que las damas suelen hacer" (MILÁN, 1874, p.289). Nesse capítulo, temos uma intensa performance musical de sonetos ao longo de uma série de 22 peças de autoria do próprio Milán, "um concierto para voz y vihuela, otramanera de disfrute del texto literario" (RAVASINI, 2014, p. 343). A série é provocada por um convite ao canto feito por d. Leonor: "laprimeraquiero ser yo, que os 
mando me canteis sonetos vuestros[...]" (MILÁN, 1874, p.308). Os poemas cantados um após o outro funcionam como um cancioneiro, contando os passos de um enamorado, um sujeito lírico apaixonado e sofredor, como podemos ver na poesia de Garcilaso, Camões ou Diogo Bernardes.

Na tradução que Boscán faz do Cortesão de Castiglione, em 1534, encontramos a valorização desse tipo de performance músico-poética em detrimento da polifonia (canto a várias vozes):

[...] mas aún pienso que es mejor cantar con una vihuela. Porque toda la dulzura consiste casi en uno que cante solo, y con mayor atención se nota y se entiende el buen modo y el aire no ocupándose los oídos en más de una sola voz que si se ocupan en muchas, y allí entonces se juzga más delgadamente un yerro por pequeño que sea, lo que no acaece si muchos cantan, porque el uno ayuda al otro. Mas por lo que yo estoy mejor con el cantar con una vihuela, es por lo que vulgarmente llamamos recitar, el cual da tanta gracia y fuerza a las palabras, que es maravilla (BOSCÁN, 1984, p.152 apud GÁSSERLAGUNA, 2017, p. 29).

Outro aspecto relevante, no que se refere aos empregos do soneto em El cortesano de Milán, é o uso humorístico do poema nas práticas relativas a burlas cortesãs. Como nota InêsRavasini,

la vinculación de los sonetos con su entorno dialógico avala una interpretación jocosa y relacionada con el efímero pasatiempo palaciego: los sonetos, anclados al hic et nunc del festejo cortesano, se vuelven motes, divisas de un estado de ánimo, rúbricas de una anécdota la mayoría de las veces cómica (2014, p. 258).

O tom da voz e a intenção dramática do cantor interferiam diretamente na recepção e interpretação do poema. É o que observamos no início da segunda jornada de El cortesano, que parte da leitura jocosa de um soneto petrarquista, dramático.

La conversaciondella será declarar al principio debaxojocosidade el presente

Soneto

Con alta voz yo cantaré llorando,

Pues es llorar cantar penalidades,

Á fin de bien diré muchas verdades,

Que muchos van por esto sospirando.

Mi fin será que vayan escuchando

Para mostrar las fieras crueldades,

Qu'el dios de amor, por campos y ciudades,

Á sombras va con sombras espantando.

$[\ldots]$

(MILÁN, 1874, p. 89) 
A declamação do poema é seguida por uma série de interpretações provocativas e cômicas, transformando o soneto de tema sério em poema chistoso, como propunha a segunda jornada: "declarar baxojocosidad". Tal inversão cômica da leitura de sonetos petrarquistas, originalmente de tom dramático, tão ao gosto da geração de Camões, pode indicar uma efetiva prática de leitura e de performance deste gênero de poesia. Imaginemos "Eu cantei já, e agora vou chorando" ou "Com grandes esperanças já cantei", de Camões, que num famoso soneto "converte em choro o doce canto", ou ainda poemas como "Cantei um tempo agora choro a guerra", de Diogo Bernardes, sendo recitados ou cantados "baxojocosidad". Tal possibilidade abre a janela para que outros sonetos, mesmo aqueles de aparência séria e filosófica, possam ter uma segunda camada interpretativa revelando um possível emprego burlesco em uma dinâmica de salão.

O soneto cantado com acompanhamento musical também está presente na novela pastoril La Diana, do português Jorge de Montemór (c.1520/25-1561), cantor e músico da corte, instrumentista e poeta, apelidado Montemayor na Espanha, onde passou grande parte de sua vida produtiva. La Diana, escrita em castelhano, publicada em Valência, em 1558/59, alcançou grande difusão em sua época, ganhando muitas edições no século XVI e no XVII e sendo traduzida para o inglês, o francês e o alemão, tornando-se um verdadeiro best-seller. Em Portugal, em 1581, a novela pastoril entrou para o índex dos livros proibidos. Apesar disso, a Diana era lida e empregada em saraus domésticos, como atestam os depoimentos colhidos pela Santa Inquisição na Bahia em 1592, em que alguns moradores da colônia portuguesa são denunciados por lerem a novela pastoril de Montemór ${ }^{8}$.Nas confissões dos acusados, podemos observar que muitos afirmam ter lido o livro "perante" alguém, indicando a vocalização. Uma parte dos acusados fazia parte da elite colonial e empenha-se em atividades culturais cortesãs, como o poeta e músico Bartolomeu Fragoso e a senhora Paula Sequeira, ele licenciado, poeta e músico, ela dona de uma casa onde ocorriam encontros de música e poesia. Um dos crimes de Paula Sequeira vinculava-se às dinâmicas de salão da sociabilidade cortesã: "mandava cantar per um moço musico de nome Manuel que tinha em casa as cantigas da dita Diana. (PORTUGAL, proc. 3307)" (apudBRAGA, 2017). O livro impresso não era apenas objeto da leitura silenciosa ou individual, era igualmente lido em grupo, em voz alta, diante de uma audiência, e também se prestava ao espetáculo cortesão, às práticas envolvendo música e poesia ocorridas nos salões da nobreza, nas casas dos letrados ibéricos e da elite colonial. A Diana era um livro extremamente prático no que toca a sua materialidade, impresso no pequeno formato in $8^{\circ}$, tamanho ideal para ler levado no bolso, como um songbook portátil.

A Diana é uma novela pastoril que entrelaça narrativa e poesia, em que a música instrumental e o canto estão maciçamente presentes. Montemór escreve do ponto de vista de um profissional do canto e da música, e encena um longo espetáculo visual e musical em sua novela pasto- 
ril, uma narrativa em que temos uma estrutura quase operística ou como um embrião de técnicas operísticas, como já foi observado (DAMINANI, 1983; MONTERO, 1996). A ópera teria início apenas na primeira década do século seguinte,com L'Orfeo, de Claudio Monteverdi, em que talvez ainda reverbere o tremendo sucesso da Diana, precursora das novelas pastoris ibéricas e onde encontramos um belo canto de Orfeu.

Ao longo dos sete livros da Diana de Montemór, as personagens tocam diversos tipos de instrumentos e cantam romances, vilancicos, oitavas, liras, canções, tercetos, sextinas e sonetos. A novela representa o mundo idealizado dos pastores, mas certamente algo da experiência prática musical de Montemór como cantor a serviço de damas da alta nobreza, como da corte de D. Joana, mãe de D. Sebastião, deve transparecer nas frequentes cenas musicais. Como nos livros de música de vihuela, também em La Diana o soneto é cantado a uma só voz (monodia) e acompanhado por um instrumento de corda tangido pelo cantor, como a rabeca (rabel) ou a harpa - ao contrário de outros gêneros, como o vilancico, cantados em polifonia e com vários instrumentos. A escolha pelo conjunto voz e cordofone reflete, segundo ensina o musicólogo Nino Pirrotta, uma preferência humanista. Também versos de Ovídio e Virgílio eram cantados com esse arranjo intimista (PIRROTA, 1985, p.464). Podemos pensar no soneto como uma ária, uma cena musical subjetiva, em que uma personagem canta seus dramas pessoais e amorosos. E é exatamente dessa forma que são encenados os dois primeiros sonetos em La Diana, cantados primeiro por Selvagia, "com muchagracia e suavidad”, ("Yahe visto yo a mis ojos más contento"), e depois por Sireno ("Andad, mis pensamientos, do algún dia"), que entram em cena resumindo em um poema os seus dramas principais.

Por vezes o soneto faz parte de uma cena musical composta por mais de um poema cantado. Como no livro segundo da Diana, em que o soneto "Gastando fueel amor mis tristes anos" é seguido, nessa ordem, por uma sessão instrumental de "cuatro violas de arco y um clavicordio", por uma canção em redondilhas cantada a quatro vozes, e ainda por outros números musicais (MONTEMÓR,1996, p.112) tocados pelos personagens.

[...] volví a oír al mi Don Felis, el cual entonce comenzaba, al son de una harpa que muy dulcemente tañía, a cantar este soneto:

SONETO

Gastando fue el amor mis tristes años

En vanas esperanzas y escusadas;

Fortuna de mis lágrimas cansadas

Ejemplos puso al mundo muy extraños;

El tiempo, como autor de desengaños,

Tal rastro deja en él de mis pisadas

Que no habrá confianzas engañadas

Ni quien de hoy más se queje de sus daños. 


\begin{abstract}
Aquella a quien amé cuanto debía
Enseña a conocer en sus amores

Lo que entender no pude hasta ahora.

E yo digo gritando noche y día:

¿no véis que os desengaña, oh amadores,

Amor, fortuna, el tiempo y mi señora?

(MONTEMAIOR, 1996, p.112)
\end{abstract}

Podemos aproximar o soneto cantado de Montemór a vários de Camões, que, no mesmo estilo dramático, trazem implícita uma voz, uma encenação em que quase podemos sentir o corpo e a emissão vocal, e até mesmo a música ao estilo humanístico requerido pelos sonetos, com o acompanhamento da viola de mão portuguesa:

Quando de minhas mágoas a comprida

Maginação os olhos madormece,

Em sonhos aquel'alma m’aparece

Que para mim foi sonho nesta vida.

Lá nũasoidade, onde estendida

A vista pelo campo desfalece,

Corro para ela, e ela então parece

Que mais de mim se alonga, compelida.

Brado: Não me fujais, sombra benina.

Ela (os olhos em mim cum brando pejo,

Como quem diz que já não pode ser),

Torna a fugir-me, e eu gritando, Dina!

Antes que diga Mene, acordo, e vejo

Que nem um breve engano posso ter.

(CAMÕES, 2018, p.87)

Ou, ainda:

De vós me aparto, ó vida, em tal mudança,

Sinto vivo da morte o sentimento,

Não sei pera que é ter contentamento,

Se mais há de perder quem mais alcança.

Mas dou-vos esta firme segurança,

Que posto que me mate meu tormento,

Pelas águas do eterno esquecimento

Segura passará minha lembrança.

Antes sem vós meus olhos se entristeçam,

Que com qualquer cousoutra se contentem,

Antes os esqueçais, que vos esqueçam.

Antes nesta lembrança se atormentem,

Que com esquecimento desmereçam

A glória que em sofrer tal pena sentem.

(CAMÕES, 2018, p.67) 
Apesar de não terem sido escritos diretamente para a música, os sonetos portugueses do século XVI, como os de Luís de Camões, faziam parte do entretenimento cortesão, das dinâmicas de salão, e se prestavam ao canto com acompanhamento instrumental. Em alguns sonetos podemos sentir quase que uma demanda da voz, um espaço a ser preenchido pela interpretação musical do poema, espaço este não contemplado pela leitura silenciosa. Assim como na Bahia do século XVI, cantavam-se e tocavam-se "cantigas", ou seja, poemas de diversos gêneros, da Diana de Montemór, oucomo na Espanha os livros de vihuela eram usados para a realização musical e vocal de sonetos, também em Portugal tais práticas, comuns ao sistema literário e cultural ibérico, se davam. Pensar os sonetos além de seu registro material escrito e de sua leitura silenciosa, compreendê-los na dimensão da performance, do corpo, da voz e da música, pode ampliar o campo hermenêutico dos poemas, apontando novas possibilidades interpretativas.

O vihuelista Miguel de Fuenllana, em sua Orphenica Lyra- que também inclui sonetos -, impressa em 1554,quando a geração de Camões já estava em plena atividade poética nos salões de Lisboa, afirma que a letra é "a alma de todas as composições, pois mesmo que qualquer obra composta por música seja muito boa, faltando-lhe a letra parece que carece de verdadeiro espírito"9 (apud POPE, 1961, p.367). Segundo os vihuelistas, a música, ao acompanhar a poesia, fazia com que as palavras ganhassem relevo, clareza e significado, e produzia afetos, ou seja, efeitos sublimes ligados a virtudes e questões espirituais. Os versos, ao serem cantados e tocados, tinham sua expressão poética enfatizada, de forma a propiciar, nos espíritos humanos, o conhecimento das coisas divinas e humanas, conforme explica Anriques de Valderrábano no prólogo de seu livro de vihuela (POPE, 1961, p.366). O conceito neoplatônico da poesia como forma de conhecimento estendia-se, potencializado pelo canto e pela beleza do acompanhamento musical, aos versos cantados e tocados. Tais eram as concepções correntes da relação sempre tão frutífera entre música e poesia, às quais Camões, como poeta humanista, certamente não teria ficado indiferente.

\section{REFERÊNCIAS BIBLIOGRÁFICAS}

ALATORRE, Antonio. Sobre la "gran fortuna" de un soneto de Garcilaso. Nueva revista de filologia hispanica, v. 24, $\mathrm{n}^{\circ}$ 1, 1975. p. 142-177. Disponível em: <https://nrfh.colmex.mx/index.php/nrfh/article/view/461/461>. Acesso em: 1 out. 2019.

BRAGA, Isabel Drumond. Leitura e sociabilidade no feminino: Paula de Sequeira no Brasil Quinhentista. História, Franca, v. 36, e22, 2017. Disponível em: <http://www.scielo.br/scielo.php?script=sci_arttext\&pid=S0101-90742017000100404\&lng=en\&nrm=iso >. Acesso em: 2 ago. 2019. DOI: <http://dx.doi.org/10.1590/1980-436920170000000022>.

BRAGA, Teófilo. Historia da poesia portuguesa. Eopopêas da raça mosárabe. Porto: Imprensa Portuguesa Editora, 1871. 
BELTRAMI, Pietro G. Osservazionisullametrica dei siciciani e dei siculo-toscani. In:COLLUCIA, Rosario;GUALDO, Riccardo (orgs.). Daisicilianiaisiculo-toscani, lingua, metro e stile per la definizione del cânone - Atti del Convegnno (Lecce, 21-23 aprile 1998). Galatina: Gongedo Editore, 1999.

CAMÕES, Luís de. 20 sonetos. Edição comentada de Sheila Hue. Campinas: Editora da Unicamp, 2018.

CASTAGNA, Paulo. Os modos e a gênese musical em Luis de Milan. Departamento de Artes da UFPr, Revista Eletrônica de Musicologia.vol. 1.1, set. de 1996. Disponível em :<http://www.rem.ufpr.br/_REM/REMv1.1/ vol1.1/milan.html>.Acessoem: 1 out. 2019.

DAMIANI, Bruno. Montemayor's Diana, music and the visual arts. Madison: The Hispanic Seminary of Meieval Studies, 1983.

FRANCO, Marcia Arruda. O casamento da música e da poesia no Cancioneiro de Resende. Convergência Lusíada, n. 38, jul. - dez. 2017. p. 101-115.

GÁSSER LAGUNA, Luis. Recitado musical en El Cortesano de LuisMilán. Emblecat, Revista de l'AssociacióCatalana d'Estudis d'Emblemàtica, Art i Societat, $\mathrm{n}^{\circ}$ 6, 2017. p. 15-42.

LÓPEZ ALEMANY, Ignacio. El sonsoneto y la práctica poética cortesana del siglo XVI. Revista de Estudios Hispánicos, t. 50, n 3, out. 2016. p. 583-603.

MILÁN, Luís. Libro de música de vihuela de mano intitulado El maestro[... ] compuesto por don LuysMilan, dirigido al muy alto [et] muy poderoso [et] inuictissimopri[n]cipe don Juhan, por la gracia de Dios, rey de Portugal $y$ de las yslas [et]c. Valencia: Francisco Díaz Romano, 1536.

- Libro de motes de damas y caballeros intitulado el juego de mandar. Valencia: Francisco Díaz Romano, 1535.

. Libro intitulado El Cortesano. Valencia: Ioan de Arcos, 1561.

Libro intitulado El cortesano, compuesto por D. Luís Milán. Madri: Imprenta y estereoptipia de Aribau y Ca, 1874.

MONTEMAYOR, Jorge de. La Diana. Edición de Juan Montero. Estudio preliminar de Juan Bautista de Avalle-Arce. Barcelona: Crítica, 1996.

MONTERO, Juan. Prologo. In: MONTEMAYOR, Jorge de. La Diana. Barcelona: Crítica, 1996.

MORAIS, Manuel. A viola de mão em Portugal (c.1450-1789). Nassarre: Revista aragonesa de musicologia, v. 22, $\mathrm{n}^{\circ} 1,2006$. p. 393-462.

MUDARRA, Alonso. Tres libros de musica en cifra para vihuela en cifras e canto de órgano [...]. Sevilha: Juan de León, 1546. 
OTAOLA GONZÀLEZ, Paloma. Poesía italiana en los libros de música para vihuela del siglo XVI. In: BOTTA, Patrizia (coord.).Rumbos del hispanismo en el umbral del cincuentenario de la AIH, v. 3, [Siglo de Oro (prosa y poesía) / coord. por María Luisa Cerrón Puga], 2012.p. 321-329.

OUVRARD, Jean-Pierre. Le sonnet ronsardien en musique: du Supplément de 1552 à 1580. Revue de Misicologie, t. 74, nº 2, Les Musiciens de Ronsard, 1988.p. 149-164.

PIRROTA, Nino. Musica e Umanesimo. Lettereitaliane, v.37, n. 4, out./dez. 1985.p. 453-470. Disponível em: JSTOR, www.jstor.org/stable/26263471. Acesso em: 1 out. 2019.

PISADOR, Diego. Libro de música de vihuela. Salamanca: Diego Pisador, 1552.

POPE, Isabel. La vihuela y su música en el ambiente humanístico. Nueva Revista de Filología Hispánica, 15, n³/4, 1961, p. 364-376.

RAVASINI, Inés. Poesía y vida de corte: los sonetos en el cortesano de Luis Milán. Revista de poética medieval, nº 28, 2014. p. 335-357.

RIBEIRO, Bernardim. Trovas de dous pastores s. Silvestre e Amador. Feytas por BernaldimRibeyro. Novamente empremidas com outros dousromãces com suas grosas: que dizem. O belerma. E justa fue mi perdicion. E passando el mar Leandro. Lisboa: GermãoGalharde. 1536. Disponível em: <http://purl.pt/6957>. Acesso em: 1 out. 2019.

RONCAGLIA, Aurelio. Sul "divorziotramusica e poesia” nelduecento italiano. In:ZIINO, Agostino (org.), L'Ars Nova Italiana delTrecento IV. AttidelTerzo Congresso Internazionale sul tema La musica ai tempidel Boccaccio e i suoirapporticonlaletteratura(Siena-Certaldo, 19-22 luglio 1975). Certaldo: Centro distudisull'Ars Nova italiana delTrecento, 1978. p. 365-91.

RONSARD, Pierre de. Abregé de lartpoetique François. Londres, Hacon\&Ricketts, 1903.

VAINFAS, Ronaldo (org.). Confissões da Bahia. São Paulo: Companhia das Letras, 1997.

VIGNES, Jean. Poésie en musique: des Amours de Ronsard au "supplément musical". Fabula / Les colloques, Relire Les Amours de Ronsard. Disponivel em: http://www.fabula.org/colloques/document3035.php>. Acesso em:24 jul. 2019. 


\section{NOTAS}

1 Professora do Instituto de Letras da Universidade do Estado do Rio de Janeiro, pesquisa principalmente as práticas letradas e os discursos quinhentistas portugueses, com ênfase nos estudos camonianos e nos relatos de viagem. É autora de diversos artigos e edições comentadas, como Primeiras cartas do Brasil (Zahar, 2006) e 20 Sonetos de Luís de Camões (Editora da Unicamp, 2018).

2“[...]quando, comoe a questopunto pare necessario, ci si Volga ad analizzarepiùda davvicinoquellanozionedi 'divorciotramusica e poesia' Che di per sé risulta ambígua, rappresentando in realtà non um attosempliceedimprovvisodidistacco, mapiuttostolultimoesitodún processo dispecificazione intrinsecamente complesso" (RONCAGLIA, 1978, p. 367).

3 Cf. RIBEIRO, 1536.

4 Luís Milán, emEl cortesano, registra a performance de canto e vihueladeste romance e de suas glosas: "[... ] lo primero que cantaré será la glosa que hice al romance de Belerma y Durandarte quando se dejó de servirla, y es ésta: Ya no es él, perdido está/[...]Durandarte, Durandarte[...]" (MILÁN, 1847, p. 123).

5 "et d'une réalisation décisive pour accomplir l'union de la poésie et de la musique ardemment désirée par les humanistes en général et par Ronsard en particulier” (VIGNES, 2016, p.6).

6 "J'ai faict imprimer, et mettre à la fin de ce présent livre, la Musique, sur laquelle tu pourras chanter une bonne partie du contenu en icelluy [...]". (RONSARD apudOUVRARD, 1988, p. 152)

7 “[...] car la Pöesie sans les instruments, ou sans la grace d'une seule, ou plusiers voix, n'est nullement agreable, no plus que les instruments sans estre animez de la mélodie d'une plasainte voix". (RONSARDapudVIGNES, 2016, p,2)

8 Cf. Confissões da Bahia, editado por Ronaldo Vainfas (Companhia das Letras, 1997).

9“[... [elanima de qualquiera compostura, pues aunque qualquier obra compuesta de música sea muy buena, faltándole la letra parece que carece de verdadero espírito" (apud POPE, 1961, p.367). 